Article

\title{
Bi-Level Planning Model of Charging Stations Considering the Coupling Relationship between Charging Stations and Travel Route
}

\author{
Haixiang Zang ${ }^{1,2, *(\mathbb{D}) \text {, Yuting Fu }}{ }^{1}$, Ming Chen ${ }^{3}$, Haiping Shen ${ }^{3}$, Liheng Miao ${ }^{3}$, Side Zhang ${ }^{1}$, \\ Zhinong Wei ${ }^{1}$ and Guoqiang Sun ${ }^{1}$ (D) \\ 1 College of Energy and Electrical Engineering, Hohai University, Nanjing 211100, China; \\ 171306030005@hhu.edu.cn (Y.F.); ade_hhu@163.com (S.Z.); wzn_nj@263.net (Z.W.); \\ hhusunguoqiang@163.com (G.S.) \\ 2 Jiangsu Key Laboratory of Smart Grid Technology and Equipment, Nanjing 210096, China \\ 3 Wuxi Power Supply Company, State Grid Jiangsu Electric Power Co. Ltd., Wuxi 214061, China; \\ 13585086073@139.com (M.C.); hpshen@126.com (H.S.); miaoliheng@21cn.com (L.M.) \\ * Correspondence: zanghaixiang@hhu.edu.cn; Tel.: +86-137-7071-9919
}

Received: 14 June 2018; Accepted: 10 July 2018; Published: 12 July 2018

\begin{abstract}
The major factors affecting the popularization of electric vehicles (EV) are the limited travel range and the lack of charging infrastructure. Therefore, to further promote the penetration of EVs, it is of great importance to plan and construct more fast charging stations rationally. In this study, first we establish a travel pattern model based on the Monte Carlo simulation (MCS). Then, with the traveling data of EVs, we build a bi-level planning model of charging stations. For the upper model, with an aim to maximize the travel success ratio, we consider the influence of the placement of charging stations on the user's travel route. We adopt a hybrid method based on queuing theory and the greedy algorithm to determine the capacity of charging stations, and we utilize the total social cost and satisfaction index as two indicators to evaluate the optimal solutions obtained from the upper model. Additionally, the impact of the increase of EV ownership and slow charger coverage in the public parking lot on the fast charging demands and travel pattern of EV users are also studied. The example verifies the feasibility of the proposed method.
\end{abstract}

Keywords: electric vehicle; fast charging station; slow charging; bi-planning model; travel success ratio

\section{Introduction}

The transportation sector constitutes a primary source of greenhouse gas emission and energy consumption. In the United States, the transportation sector is responsible for $30 \%$ of the $\mathrm{CO}_{2}$ emission [1] and one third of the energy consumption [2]. The energy shortage, coupled with the problem of environmental pollution, has brought worldwide attention to electric vehicles (EVs) which brings great environmental and social benefits with zero tailpipe emissions and a lower level of noise pollution. Many countries have already formulated relevant policies to encourage research into EVs and promote their use [3,4]. For example, countries like France, the Netherlands, and Germany have announced plans to ban the sale of fuel vehicles. Nie et al. [5] proposed a modeling framework to optimize the design of incentive policies. Kontou et al. [6] proposed a framework for minimizing the social cost of replacing gas-powered vehicles with battery electric vehicles (BEVs). Additionally, the result shows that it takes 6-12 years for 80\% of conventional vehicles to be replaced with EVs. However, the proportion of EVs in all cars still remains low and the major factors that influence the popularization of EVs are the limited travel range and the lack of charging infrastructure. Surveys show that the majority of customers would expect 300 miles of travel range [7] while, for the 
time being, EVs can only provide a range of 100 miles or so with a full battery. In order to make up for the limited travel range, to mitigate range anxiety, and to promote the penetration rate of EVs, it is of great importance to plan and build up more fast charging stations, taking into account the faint possibility of increasing the travel range in a short time [8].

Recent years have seen a growing number of research on the planning of charging infrastructures. The charging demand constitutes the basis for planning. In [9-12], emphasis was laid on researching the charging demand and mobility of the EVs according to the uncertainty of traveling. In the classic studies that focus on the planning of charging stations, the charging demand is usually regarded as fixed [13-18]. In [13], the considered charging demand appears at the destination. Dong et al. [14] assumed that EV would be charged when it was going to run out of power. Frade et al. [16] took centroids of census blocks as charging points, whereas Xiang et al. [18] placed charging stations at traffic nodes. This type of planning usually applies a clustering algorithm to the siting of charging stations [13-15] or minimizes the distance between charging points and charging stations [16,17]. However, some researchers consider that it is inappropriate to regard charging demands as static and fixed [19], because this type of planning can hardly reflect the mobility of EVs and, actually, the majority of EV users would not make a special visit to charging stations. The flow-capturing location model (FCLM) is widely used to maximize the captured flows based on the assumption that the flow is captured when at least one charging station on the path [20-22]. The model was used in [19,23-26]. Among them, Wang et al. [23] considered the stochastic characteristics of travel patterns based on the classic FCLM, and Yao et al. [24] proposed a multi-objective model to minimize the overall annual cost and simultaneously maximize the captured traffic flow. In [23,25], an extended version of the FCLM is employed, which is referred to as the flow-refueling location model (FRLM), is employed. The model considers that a combination of two or more facilities may be needed to refuel a flow [27]. However, FCLM and FRLM both ignored the flexibility of users, which indicated that users might accept slightly longer trips to charge their vehicles. Kuby and Lim [28] proposed a model called the multipath refueling location model (MPRLM) based on FRLM. The model considers multiple paths and is constrained by the condition that it should satisfy all travel demands. The installing and operating cost is represented by weights that set on the candidate site, and its objective is to minimize the total cost.

Moreover, many literatures aim to minimize the total social cost of charging infrastructure [29-31], which normally includes fixed investment cost, land cost, the construction cost of fast chargers and other costs. In $[27,28,32]$, the user's trip feasibility is considered when planning charging stations. Among them, Chung and Kwon [27] divided the traffic nodes into main nodes and sub-nodes. First, fast charging stations are placed at all main nodes. Then the remaining charging stations are set, following the principle that the distance between adjacent charging stations should not exceed the maximum travel range of EVs. In [33-35], data-driven approaches are adopted to plan charging infrastructures. Dong et al. [33] analyzed the impact of different deployment levels of public charging infrastructure on reducing EV range anxiety. He et al. [34] considered users' spontaneous adjustments, as well as interactions of traveling and recharging decisions. Yang et al. [35] proposed a data-driven optimization approach based on large-scale GPS trajectory data.

When planning fast charging stations, we find that some researchers suggest siting while sizing $[17,36]$ and others suggest siting before sizing $[18,24,37]$. For sizing fast charging stations, the queuing theory is most commonly applied. In $[18,36]$, the capacity of the charging station was determined by aiming at the minimum number of chargers and was constrained by the average waiting time. In $[14,24]$, similarly based on the queuing theory, the capacity was determined by the objective to minimize the sum of the charger cost and the waiting cost of EV users. However, it is difficult to calculate and determine the average arrival rate of EVs and the charger cost, so there would be a very large possibility of inaccuracy in sizing. As a result, a hybrid method based on queuing theory and the greedy algorithm [25] is applied in this paper to determine the capacity of fast charging stations. This method enables us to allocate a certain number of chargers at each station based on the relative 
system density of stations without any prior knowledge of the arrival rate at each station, which will effectively reduce congestion at charging stations and avoid an unreasonable allocation of resources.

This paper centers on planning fast charging stations in urban areas. Its primary purpose of the charging infrastructure is to fulfill the need of EV users, and the subsequent purpose is to minimize the total social cost against a background of low EV penetration nowadays. Therefore, we propose a multi-objective bi-level planning model, consisting of upper and lower models. The upper model addresses the siting problem to maximize the travel success ratio, and the lower model assesses possible plans to obtain the optimal plan based on the satisfaction index and total social cost. The main contributions of this paper are:

- In this study, we consider the coupling relationship between EV users' travel routes and the location of charging stations. The shortest path would be the best choice, however, when it could cannot meet the traveling demand, we search other routes passing the fast charging stations within a certain deviation so as to analyze the trip feasibility.

- In order to simulate the process of users heading for charging stations to charge, we accord priority consideration to charging when the state of charge (SOC) is less than the range anxiety threshold, and then to charge on relatively sufficient battery. Following this method, we obtain the number of EVs charged at each station, which enables us to achieve a more reliable and practical sizing result.

- Based on the charging times and deviation, we propose the concept of the satisfaction index. The satisfaction index can reflect the convenience that the location of the charging stations would bring to the users.

- In this research, we combine slow charging in the public parking lot and fast charging in the fast charging station, and research the impact of the increase of EV ownership and coverage of slow chargers on the fast charging demand and the travel success ratio.

The rest of the paper is organized as follows: Section 2 presents a model for uncertain travel patterns of EVs. Section 3 presents the impact of the location of fast charging stations on the travel route, analyzes the feasibility of the travel route and simulates the process of users heading for the stations to recharge. Section 4 proposes the upper model based on the travel success ratio for the siting of charging stations. Section 5 proposes the lower model based on satisfaction index and the total social cost for the optimal planning scheme. Section 6 focuses on the trip feasibility considering slow charging at the destinations. The test case is shown in Sections 7 and 8 presents the conclusions and future work. Figure 1 shows a block diagram of the proposed method to determine the optimal plan of charging stations and additional research on slow charging.

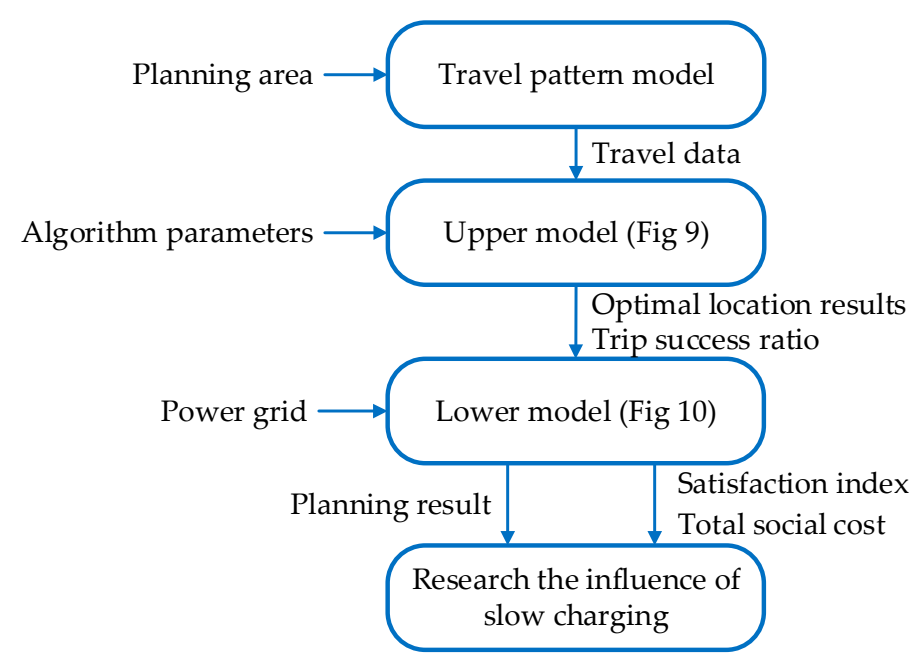

Figure 1. A block diagram of the proposed method. 


\section{Uncertainty Modeling of Travel Pattern}

'Trip chain' refers to the series of trips made by individuals for one or more purposes. Based on the number of daily trips and destinations, along with the daily travel distance as a constraint, we use a closed-loop trip chain that originates and ends at the home to model the EV travel pattern, avoiding fixing the charging demand to a point, in order to reflect the mobility of EVs. Figure 2 is a closed-loop trip chain with $i$ purposes where the dashed lines indicate the driving process.

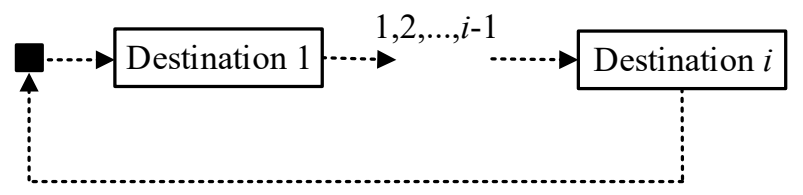

Figure 2. The schematic diagram of a closed-loop trip chain.

Research has shown that the EVs do not affect EV users' lifestyle [38]. Therefore, in this study, we assume that EVs have a similar driving pattern as conventional vehicles.

\subsection{Daily Trips}

This paper is concerned with the private vehicle and we assume that an EV user would charge the vehicle at home the night before their trip and depart on a full battery. From the statistics of the 2009 National Household Travel Survey (NHTS) [39], we obtain the probability distribution of daily trips per vehicle, as is shown in Figure 3. We denote daily trips as $n_{t}$, and the number of destinations is $n_{t}-1$. Based on the probability distribution of daily trips, we use the Monte Carlo simulation (MCS) to obtain the number of daily trips per vehicle.

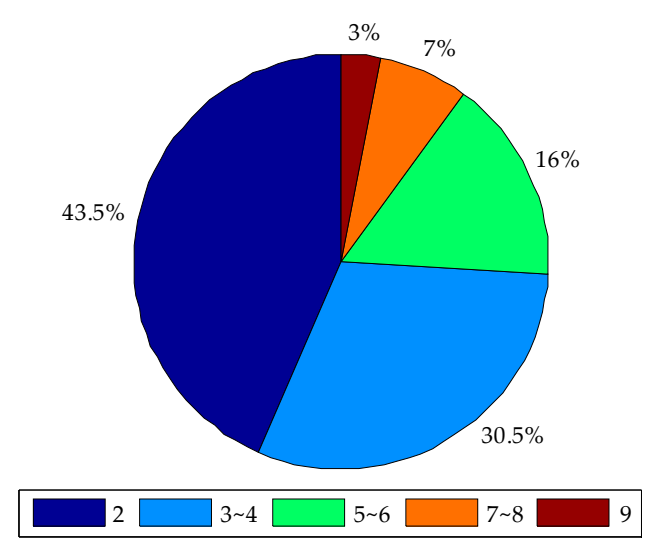

Figure 3. The probability of daily trips per vehicle.

\subsection{Destination of Trip}

The purposes of the trips are mainly classified into five categories in the relevant research: home (H), work (W), shopping and eating (SE), social and recreational (SR), and other family/personal errands $(\mathrm{O})$. Among them, SE, SR, and O often overlap in the commercial area. Therefore, following the method proposed in $[10,40,41]$, we classify the study area into the residential area $(\mathrm{H})$, industrial area (W), and commercial area (SE/SR/O).

The determination of destinations is to be seen as a Markov decision process [42]. The process of EV users traveling from the current location to the next destination is regarded as a state transition process. Each state transition process is only related to the state of the previous moment, but not of the past moments. The proportion of tour types is shown in Table 1 [39]. We turned the data into a matrix format and the spatial state transition probability matrix of users in different areas is shown in 
Equation (1) where the rows of the matrix correspond to the types of start points with $\mathrm{H}, \mathrm{SE} / \mathrm{SR} / \mathrm{O}$, and $\mathrm{W}$ from top to bottom, and the columns of the matrix correspond to the types of end points with $\mathrm{H}, \mathrm{SE} / \mathrm{SR} / \mathrm{O}, \mathrm{W}$ from left to right. The type of start point decides the corresponding row in the matrix and the type of destination can be obtained based on the probability in the row by utilizing MCS:

$$
P=\left[\begin{array}{lll}
p_{11} & p_{12} & p_{13} \\
p_{21} & p_{22} & p_{23} \\
p_{31} & p_{32} & p_{33}
\end{array}\right]=\left[\begin{array}{lll}
0.2468 & 0.5424 & 0.2108 \\
0.6750 & 0.2862 & 0.0388 \\
0.6940 & 0.2045 & 0.1015
\end{array}\right]
$$

Table 1. The proportion of tour types; $\mathrm{H}-\mathrm{H}$ : from the residential area to the residential area; $\mathrm{H}-\mathrm{O}$ : from the residential area to the commercial area; $\mathrm{H}-\mathrm{W}$ : from the residential area to the industrial area; $\mathrm{O}-\mathrm{H}$ : from the commercial area to the residential area; O-O: from the commercial area to the commercial area; $\mathrm{O}-\mathrm{W}$ : from the commercial area to the industrial area; $\mathrm{W}-\mathrm{H}$ : from the industrial area to the residential area; $\mathrm{W}-\mathrm{O}$ : from the industrial area to the commercial area; $\mathrm{W}-\mathrm{W}$ : from the industrial area to the industrial area.

\begin{tabular}{cccccccccc}
\hline Tour Type & H-H & H-O & H-W & O-H & O-O & O-W & W-H & W-O & W-W \\
\hline Proportion/\% & 11.80 & 25.93 & 10.08 & 26.58 & 11.27 & 1.53 & 8.89 & 2.62 & 1.30 \\
\hline
\end{tabular}

\subsection{Travel Distance}

The daily mileage is used as a constraint in the determination of the destination. Based on the statistics obtained from 2009 NHTS, the daily mileage follows the lognormal distribution [10] as:

$$
f_{1}(x)=\frac{1}{x \sigma_{1} \sqrt{2 \pi}} \exp \left(-\frac{\left(\ln x-\mu_{1}\right)^{2}}{2 \sigma_{1}^{2}}\right)
$$

where $x$ denotes the daily driving distance, $\mu_{1}$ and $\sigma_{1}$ represents the expected value and standard deviation of the lognormal probability density function, respectively, and $\mu_{1}=3.2, \sigma_{1}=0.88$.

Restricted by the daily travel distance, we apply MCS based on the daily trips and destination probability and obtain a closed-loop trip chain which originates and ends at home. The flowchart of the travel pattern model is shown in Figure 4.

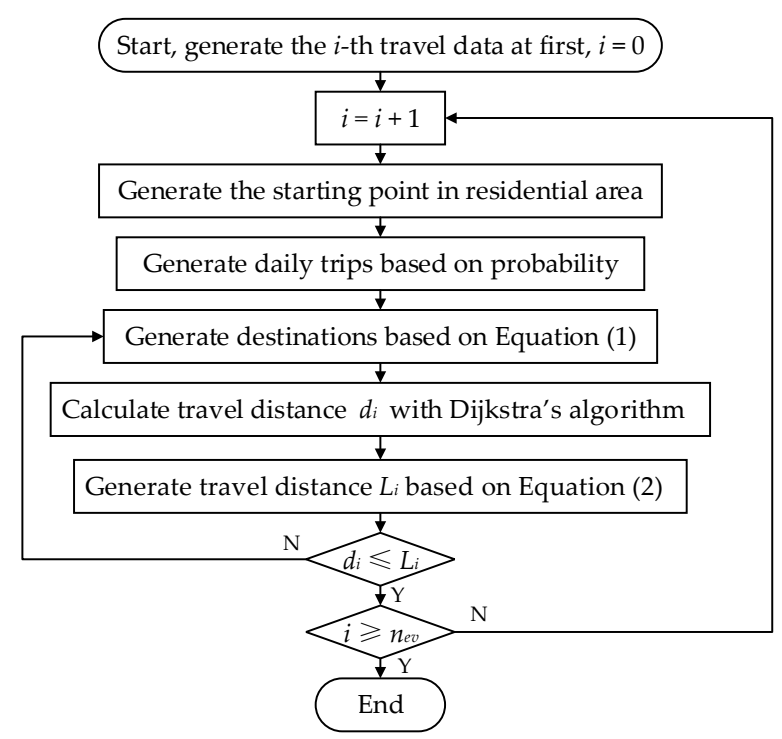

Figure 4. The flowchart of the travel pattern model. 


\section{Coupling Relationship between Charging Stations and Travel Route}

The proposed method in this paper is solved in the upper model at first to obtain a set of optimal siting solutions. In the upper model, an intelligent algorithm is utilized in which the locations of charging stations are given randomly at first. Then we analyze the feasibility of users' trips to obtain the trip success ratio under each certain siting solution which influences the optimization of the intelligent algorithm. As an important part of the proposed method, the feasibility analysis considering the coupling relationship between charging stations and the travel route is presented in this section.

\subsection{Impact of Charging Stations on Travel Route}

We assume that when the daily driving distance exceeds the EV maximum travel range along with a need of fast charging, the location of the charging stations will influence the EV user's travel route. Therefore, the principle of the shortest distance or the shortest travel time may not work in simulating the travel route.

A five-node traffic network is in Figure 5 where the number indicates the distance. The red nodes $\mathrm{b}, \mathrm{d}$, and e indicate the location of fast charging stations. We assume that there is a closed-loop trip chain which has two destinations in the traffic network with the starting point $\mathrm{O}$ (node a) and two destinations $\mathrm{D}_{1}$ and $\mathrm{D}_{2}$ (nodes $\mathrm{b}$ and $\mathrm{d}$ ). Through Dijkstra's algorithm, the shortest path of the trip chain is a-b-d-e-a with a distance of 31 . We assume that the EV maximum travel range is 13 which could not sustain $b$-d. In order to complete the trip, the user needs to charge at nodes $b$ and e to reach $\mathrm{D}_{2}$ before getting back to $\mathrm{a}$. In this case, the travel route would be a-b-e-d-e-a with a distance of 33 . Fast charging demands occur at node $b$ and node e. We find that the distribution of charging stations would affect the user' travel route. When the shortest path cannot satisfy the travel demand, the user will look for other paths. When an EV user passes by a charging station, the necessity of charge is also considered in this paper.

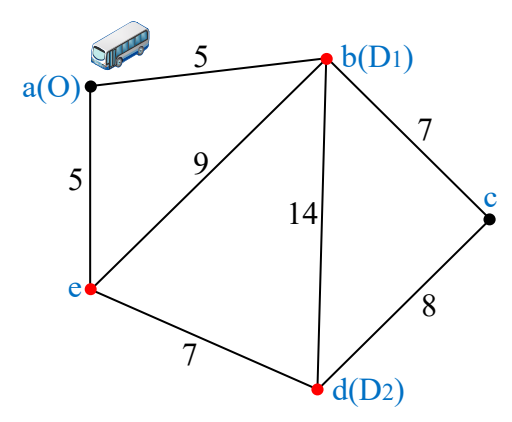

Figure 5. A five-node traffic network.

\subsection{Potential Trip Chains Considering the Location of Charging Stations}

The user will not opt for EV for a certain journey if she/he needs to charge the vehicle many times during the journey. Therefore, we believe that for each route in the trip chain, up to one charge is acceptable, otherwise the trip is deemed a failure. Assuming that the starting and ending points of a certain trip are $\mathrm{D}_{i}$ and $\mathrm{D}_{i+1}$ and the shortest distance obtained via Dijkstra's algorithm is $d_{i, i+1}$. With $\mathrm{D}_{i}$ and $\mathrm{D}_{i+1}$ as the starting and ending points, the potential route passing the charging station $\mathrm{C}_{k}$ comprises of the shortest path from $\mathrm{D}_{i}$ to $\mathrm{C}_{k}$ and from $\mathrm{C}_{k}$ to $\mathrm{D}_{i+1}$, and the distances are $d_{i, k}$ and $d_{k, i+1}$, respectively. In this case, the deviation to the shortest path $d_{v}$ is expressed as Equation (3). The definition of the deviation constraint is shown in Equation (4). If the deviation constraint is not satisfied, the route is excluded:

$$
\begin{gathered}
d_{v}=d_{i, k}+d_{k, i+1}-d_{i, i+1} \\
d_{v} \leq \lambda R
\end{gathered}
$$


where $\lambda$ represents deviation coefficient, $R$ is the maximum travel range of EVs and $\lambda R$ is the maximum deviation.

In a trip chain, we could have several potential routes for each journey among which one is the shortest route and the others are the shortest routes passing a certain charging station. In Figure 6, we find a journey with four potential routes. One is the shortest path, and the other three are routes passing the charging stations $C_{1}, C_{2}$, and $C_{3}$, respectively, where the dashed lines indicate the process of driving. Figure 7 is a schematic diagram of a set of potential trip chains where the red dots indicate the charging stations passing by.

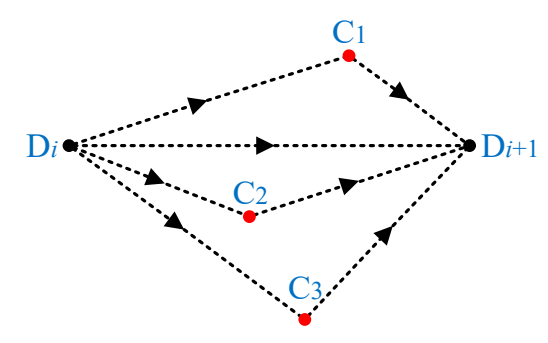

Figure 6. A journey with four potential routes.

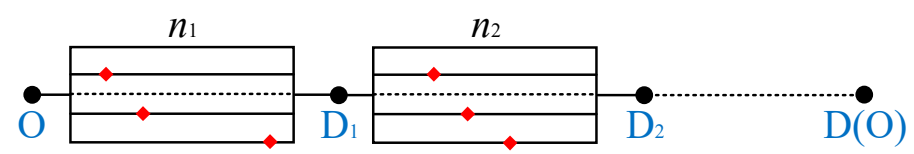

Figure 7. A set of potential trip chains.

The number of possible routes for the $m$-th journey is recorded as $n_{m}$, therefore, the total number of the potential trip chains can be obtained via Equation (5), where $n_{t}$ is daily trips. Then, we judge the feasibility of each potential trip chain; if the trip is a success, the process will terminate, otherwise, it will continue with the next trip chain until all are analyzed:

$$
n_{l}=\prod_{m=1}^{n_{t}} n_{m}
$$

\subsection{Feasibility Analysis of Trip Chains}

OD is a potential trip chain with a distance of $d$ and $R$ is the maximum travel range of EVs. It can be divided into two possible scenarios:

1. When $d \leq R$ which indicates that the traveling distance is smaller than the maximum travel range of EVs, charging is not necessary, thus the trip is a success; and

2. When $d>R$ which indicates that the traveling distance exceeds the maximum travel range of EVs, charging is necessary and we need to the judge whether the trip is a success and analyze which charging station(s) the user needs to charge at.

Here we analyze Scenario 2 while considering the range anxiety problem. When the SOC is lower than $20 \%$, the user will be imperative to charge. It is assumed that a linear relationship exists between the maximum travel range and SOC $[43,44]$. The mileage when anxiety begins is set as $R^{\prime}$ which could be calculated via Equation (6):

$$
R \prime=(1-20 \%) R,
$$

We obtain $\mathrm{D}_{i}$, which satisfies the condition $d_{O D_{i}}>R$, which means that when the EV cannot reach $\mathrm{D}_{i}$ within its travel range, it shall be charged during the range of $\mathrm{OD}_{i}$. The principle of simulating the process of users heading for charging stations to charge is as follows: 
1. If there is no charging station found in the range of $(0, R)$, the user cannot reach the next destination. The trip chain is deemed a failure.

2. If there are any charging stations found in the range of $\left(R^{\prime}, R\right)$, we will opt for the charging station closer to the start point. As the battery runs at a lower level, the user will become anxious and choose to charge immediately.

3. If there are any charging stations found in the range of $\left(0, R^{\prime}\right)$, we will choose the charging station farthest from the starting point. As the vehicle could still provide sufficient power, the charging demand is not that urgent. The time cost in the charging station would be lower for the user and she/he could charge more if she/he charges at a low-power state, thus, leading to a higher probability of a successful trip.

We assume that the user has successfully charged at charging station $\mathrm{C}_{k}$ within the range of $\mathrm{OD}_{i}$, then charging station $\mathrm{C}_{k}$ is set as the start point $\mathrm{O}^{\prime}$ and we continue to judge the feasibility of the remaining route; if that trip chain fails, we continue with the next one until all are judged. If all the potential trip chains cannot meet the demand of the journey, the journey is deemed as a failure, which indicates that the siting of the charging stations cannot satisfy the demand of the EV user.

Figure 8 shows a closed-loop trip chain with two destinations. In this study, we convert the set of tortuous routes in the urban traffic network into straight ones for analysis. In the figure, the black dot represents the destination while the red dot indicates the charging station. The solid arc is the distance boundary corresponding to $R$ with $\mathrm{O} / \mathrm{O}^{\prime}$ as the starting point, and the dotted arc is the distance boundary corresponding to $R^{\prime}$ with $\mathrm{O} / \mathrm{O}^{\prime}$ as the starting point.

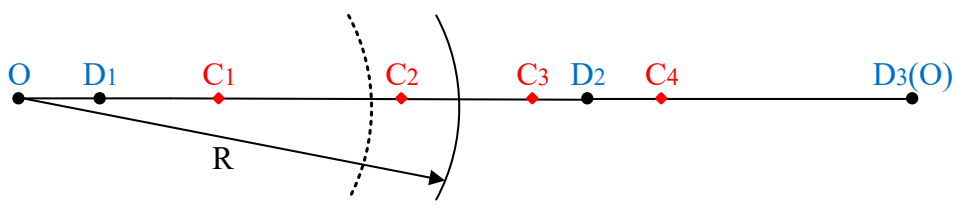

(a)

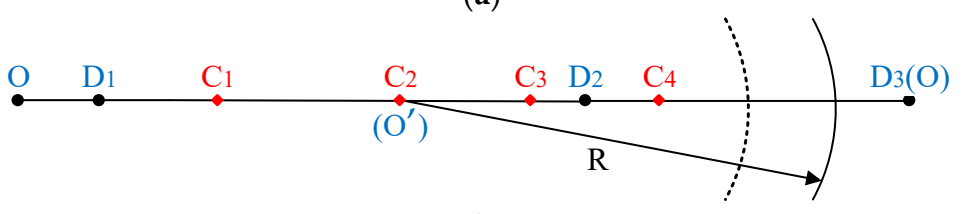

(b)

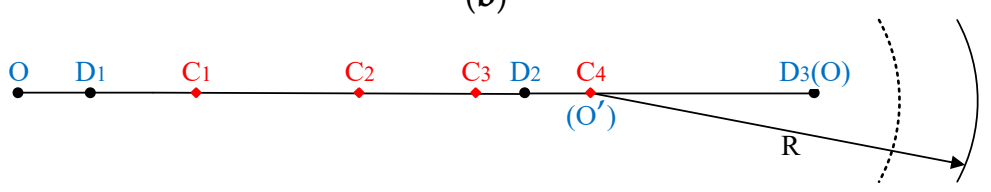

(c)

Figure 8. The feasibility analysis of the trip chain; (a) the first analysis; (b) the second analysis; (c) the third analysis.

As shown in Figure 8a, we search for the node which satisfies the condition $d_{O D_{m}}>R$ and find node $\mathrm{D}_{2}$, which means that the user needs fast charging in the range of $\mathrm{OD}_{2}$. Then we search for a charging station and find $R^{\prime} \leq d_{\mathrm{OC}_{2}} \leq R$, which indicates that the user should charge the vehicle at the charging station $C_{2}$. Thus, $C_{2}$ is set as the new starting point $\mathrm{O}^{\prime}$ as shown in Figure 8b. Repeat the procedures and we find that another fast charging is needed in $\mathrm{O}^{\prime} \mathrm{D}_{3}\left(\mathrm{C}_{2} \mathrm{D}_{3}\right)$. Following the simulating principle, the user will charge at $C_{4}$, thus, turning $C_{4}$ into a new starting point $\mathrm{O}^{\prime}$ as is shown in Figure 8c. At this moment, with $d_{O^{\prime} D_{3}\left(C_{4} D_{3}\right)}<R$, the trip chain is deemed a success. 


\section{Upper Model Based on the Travel Success Ratio}

\subsection{Model Formulation}

The upper planning model aims at maximizing the travel success ratio tsr. Considering that the planning problem does not have a high demand on the computing time, each potential trip chain will be analyzed by applying the method in Section 3.2. The binary decision variable $y_{q j}$ is defined as the success or failure of user $j ; 1$ for success, and 0 for failure. We consider that charging too many times will affect the travel experience. With $n_{c}$ as the number of fast charging times and $n_{c \max }$ as the maximum charging times, the mathematical expression for the upper model can be formulated as follows:

$$
\begin{gathered}
\operatorname{maxtsr}=\frac{1}{n_{e v}} \sum_{j=1}^{n_{e v}} y_{q j}, \\
y_{q}=\left\{\begin{array}{l}
1 n_{c} \leq n_{c \max } \\
0 n_{c}>n_{c \max }
\end{array},\right. \\
\text { s.t.d } i_{i i^{\prime}}>d_{\min }, \\
n_{c} \leq n_{c \max } \\
x_{i} \leq 1,
\end{gathered}
$$

where $n_{e v}$ denotes the number of users whose travel range exceeds the maximum travel range of EVs. $d_{i i^{\prime}}$ denotes the shortest distance between the adjacent charging stations. $d_{\min }$ refers to the shortest distance between charging stations. $x_{i}$ represents the number of charging stations at node $i$. For each traffic node, up to one charging station is acceptable.

\subsection{Solution Method}

The discrete particle swarm optimization (DPSO) algorithm is applied to solve the upper model for a set of feasible siting solutions. The maximum travel success ratio for the previous iteration is denoted by $t s r^{\prime}$ and that for the present iteration is denoted by $t s r$. For each iteration, if $\max (t s r)>t s r^{\prime}$, restore the optimal solution set, otherwise add the optimal solutions with the tsr' travel success ratio into the optimal solution set. The flowchart of the upper model is shown in Figure 9. 


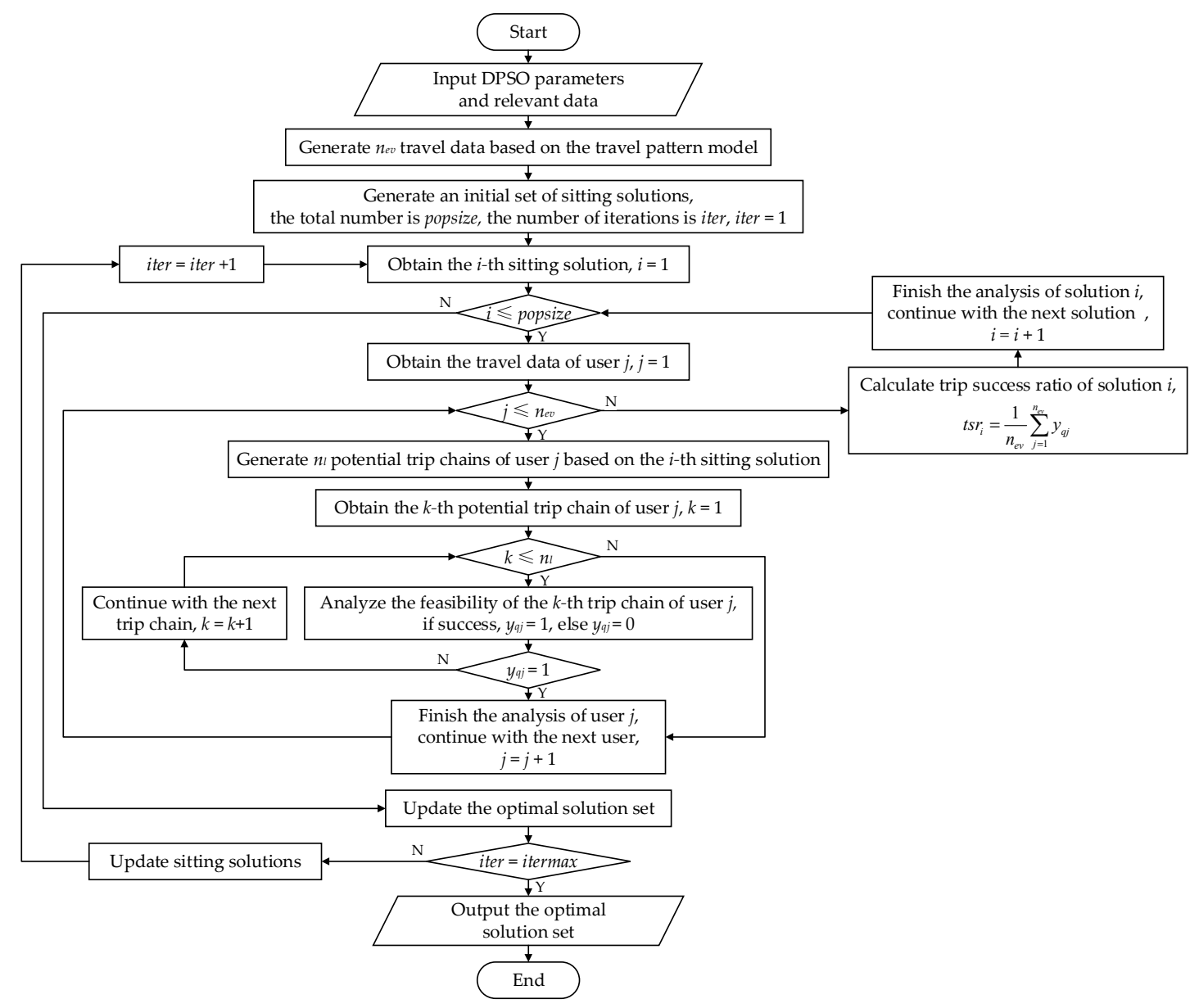

Figure 9. The flowchart of the upper model.

\section{Lower Model Based on the Satisfaction Index and Total Social Cost}

By solving the upper model based on travel success ratio, we will obtain $M$ groups of optimal solutions with the maximum success ratio, that is to say, the various groups of solutions will all lead to the same maximum success ratio. Therefore, to target the planning scheme, we apply the lower model based on the satisfaction index and total social cost.

In the lower model, based on the $M$ groups of location results, we first determine the optimal paths of EV users and the number of EVs charged at each charging stations. Then, the capacity of the charging stations for each plan can be obtained using the hybrid method based on queuing theory and greedy algorithm. Based on the siting and sizing results, we can obtain the impact of the charging stations on the power grid, and the solutions violating the constraints of the grid will be abandoned. Then we can obtain the total social $\operatorname{cost} C$ and satisfaction index $r$. The two indicators are applied to the evaluation of all the feasible solutions. If a Pareto optimal solution exists, we can use the TOPSIS method to target the optimal planning scheme. The flowchart of the lower model is shown in Figure 10. 


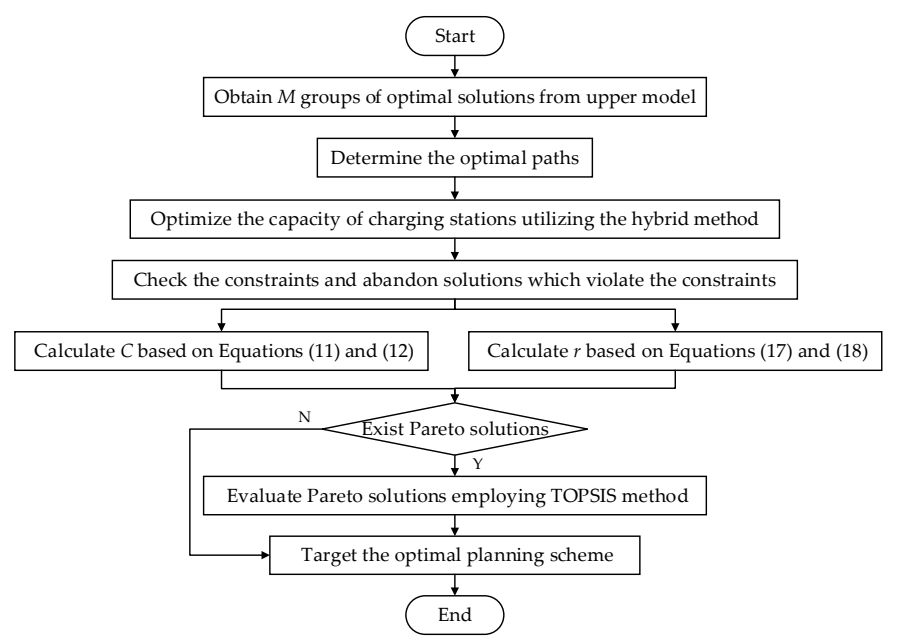

Figure 10. The flowchart of the lower model.

\subsection{Determination of the Optimal Path}

Taking into account the speed of solving the upper model, we cease the judgment when there is a feasible trip chain that meets the user's travel requirements. We assume that users can find the optimal routes and the optimal charging strategies that benefit them the most. In order to determine the charging times, the deviation, and the number of EVs served at each charging station for the sizing of the fast charging stations, it is necessary to further determine the optimal path for the user.

Based on the location results of the upper model, we apply the method described in Section 3 to all the feasible trip chains for the individual user, obtaining the charging times $n_{c}$ and the deviation $d_{v}$. The route that achieves the fewest charging times and the shortest deviation is deemed as the optimal path.

\subsection{Sizing Model Based on the Hybrid Method}

A hybrid method based on queuing theory and the greedy algorithm is employed to determine the capacity of the charging stations. After determining the optimal path, we can obtain specific data about the mileage that has been traveled when she/he arrives at a charging station to recharge. The congestion can be reflected by the system density $\rho_{i}$ by utilizing queuing theory. A greedy algorithm is used to allocate a certain number of chargers at each station based on the relative system density of stations without a prior knowledge of the arrival rate of each station. Therefore, as is shown in Equation (12), the linear function related to the number of EVs $n_{e v, i}$ served at the charging station $i$ is adopted to describe the arrival rate $\lambda_{i}$ of the charging station $i$. When it comes to the calculation of the capacity, $n_{e v, i}$ could be used to replace $\lambda_{i}$ which would reflect the system density of each charging station correctly:

$$
\lambda_{i}=f_{2}\left(n_{e v, i}\right),
$$

The service rate $\mu_{i}$ of the charging station $i$ can be obtained via Equation (13). We denote the number of chargers at the charging station $i$ as $c_{i}$, then the system density $\rho_{i}$ can be calculated by Equation (14):

$$
\begin{gathered}
\mu_{i}=\frac{1}{t_{c, i}}, \\
\rho_{i}=\frac{\lambda_{i}}{c_{i} \mu_{i}}, \\
t_{c, i}=t_{f a s t} \frac{d_{a v c, i}^{\prime}}{R},
\end{gathered}
$$




$$
d_{a v c, i}^{\prime}=\frac{1}{n_{e v, i}} \sum_{j=1}^{n_{e v, i}} d_{i, j}^{\prime}
$$

where $t_{c, i}$ is the average charging time at the charging station $i$ which is related to the SOC of EVs when they arrive at the charging station $i$ and it could be obtained via Equation (15). $t_{\text {fast }}$ is the time required for a full fast charge when the EV runs out of power. $d_{a v c, i}^{\prime}$ denotes the average mileage that has been traveled from the previous charging station to the newly-arrived charging station $i$, which can be obtained via Equation (16). $R$ is the maximum travel range of EVs. $d_{i, j}^{\prime}$ represents the mileage that has been traveled from the previous charging station to the newly-arrived charging station $i . n_{e v, i}$ is the number of EVs charged at the charging station $i$.

In the hybrid method, the total number of fast chargers for the planning area $C_{a v}$ is fixed and often much greater than the number of chargers needed. The chargers are allocated according to the system density of each charging station, that is, we fix one charger at the charging station with the highest system density until all the chargers are set. The number of charging stations is recorded as $p$ and the flowchart of sizing with the hybrid method is shown in Figure 11.

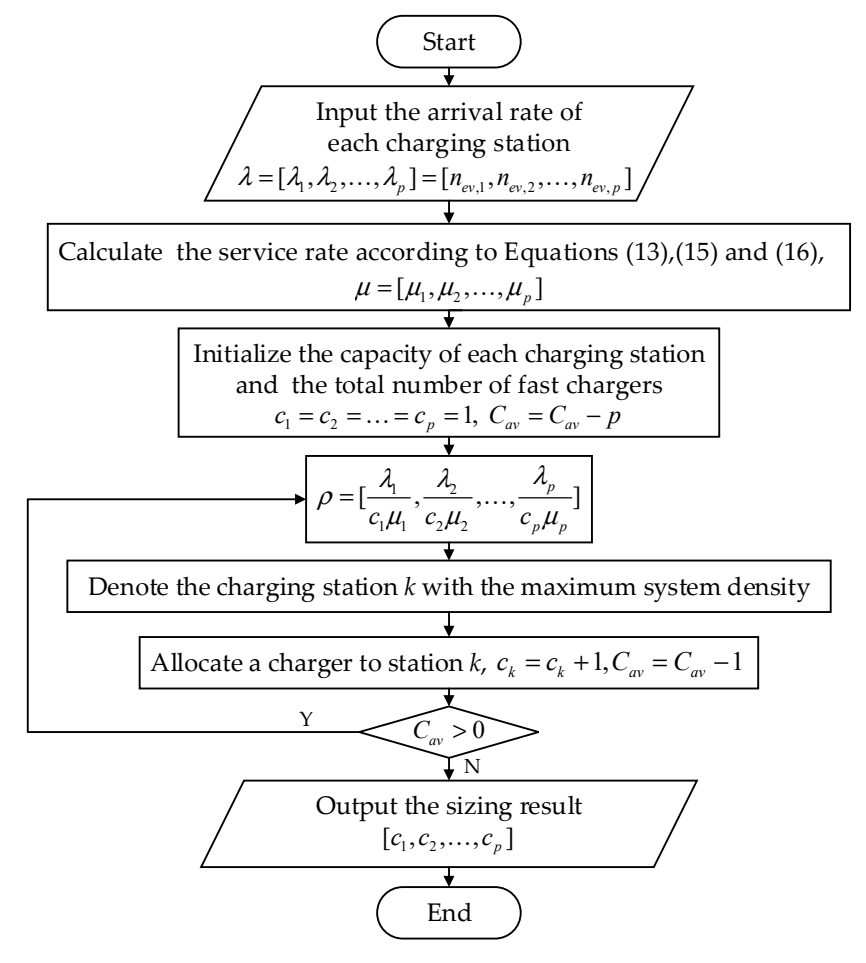

Figure 11. The flowchart of sizing with the hybrid method.

\subsection{Grid Constraints}

Several siting and sizing results can be obtained by employing the above methods while the planning result has to satisfy all the constraints of the power grid simultaneously. All the solutions obtained from the upper model will be checked and the solutions violating the constraints will be abandoned. The constraints include the equality constraints and inequality constraints, the equality constraints refer to power-flow equations and inequality constraints are shown as follows:

To retain grid stability, the allowable voltage limits for each bus are considered as:

$$
V_{m}^{\min } \leq V_{m} \leq V_{m}^{\max }\left(m=1,2, \ldots, n_{b u s}\right),
$$

where $V_{m}$ is voltage at bus $m . V_{m}^{\min }$ and $V_{m}^{\max }$ are the minimum and maximum voltage level, respectively. $n_{b u s}$ is the number of nodes in the distribution system. 
The capacity of each charging station should not exceed the maximum allowable capacity for each charging station, as shown below:

$$
S_{i} \leq S_{i}^{\max } \quad(i=1,2, \ldots, p),
$$

where $S_{i}$ is the capacity of charging station $i$, which is related to the number of chargers. $S_{i}^{\max }$ is the maximum allowable capacity of the charging station and $p$ is the number of charging stations.

Additionally, the current in the feeder should not exceed the permitted maximal current limits:

$$
\left|I_{m n}\right| \leq I_{m n \max } \quad\left(m, n=1,2, \ldots, n_{b u s}\right),
$$

where $I_{m n}$ is the current in the feeder between node $m$ and node $n . I_{m n \max }$ is the maximum allowable current in each feeder.

\subsection{Satisfaction Index}

The satisfaction index is decided by the charging times and the deviation. The mathematical expression is shown as Equation (20) where $r_{j}$ represents the satisfaction index of user $j$ and it could be obtained via Equation (21). The charging times and the deviation are combined and normalized in Equation (21), and charging times has more influence on the satisfaction index. It is noted that a smaller satisfaction index indicates a better planning scheme:

$$
\begin{gathered}
r=\frac{1}{n_{e v}} \sum_{j=1}^{n_{e v}} r_{j}, \\
r_{j}=\frac{1}{n_{c \max }+1}\left(n_{c, j}+\frac{d_{v, j}}{\lambda R}\right),
\end{gathered}
$$

where $d_{v, j}$ denotes the deviation of the user $j$ and $\lambda R$ is the maximum deviation. $n_{c, j}$ is the charging times of user $j$ and $n_{c \max }$ is the maximum charging times.

\subsection{Total Social Cost}

The total social cost includes the construction and investment cost of charging stations and the waiting cost of users. The construction and investment cost of charging stations is mainly composed of three parts: the fixed investment cost, land rental cost, and the construction cost of the fast chargers; the land rental cost is considered as a five-year rental cost. The waiting cost of users is related to the waiting time in a charging station and time cost per hour. The mathematical expression of the construction and investment cost is shown as Equation (22) [17] and the waiting cost of the users is shown as Equation (23):

$$
\begin{gathered}
C_{1}=\sum_{i=1}^{p}\left(C_{i n i t, i}+s C_{l a n, i} c_{i}+P_{c h} C_{c o n}\left(c_{i}-1\right)\right), \\
C_{2}=\sum_{i=1}^{p} c_{w w i} t_{c, i} T_{f y} n_{e v, i},
\end{gathered}
$$

where $C_{i n i t, i}$ represents the fixed investment cost for charging station $i$. We classify the charging stations according to the number of fast chargers for each charging station and the fixed investment cost is greatly depending on the level of the charging station [35]. $s$ denotes the area occupied by a fast charger including the parking area. $C_{l a n, i}$ represents the land rental cost for five years, which is related to the type of the area. $c_{i}$ is the number of chargers at the charging station $i . P_{c h}$ is the charger rated power while $C_{c o n}$ refers to the construction cost of the fast charger. $c_{w, i}$ is the time cost per hour for each user which is related to the location of the charging station $i . t_{c, i}$ is the average charging time at the charging 
station $i . T_{f y}$ is the days in five years. $n_{e v, i}$ is the number of EVs charged at the charging station i. $p$ is the number of charging stations.

The land rental cost in residential areas and industrial areas is lower than the commercial areas, normally, while users only have a few activities to engage in when she/he is waiting for the recharge in these areas and the traffic attracted by the charging station will bring on more problems in residential areas than the others. Accordingly, we consider the construction and investment cost of charging stations and the waiting cost of users at the same time. The time cost in the residential areas is the highest and in commercial areas, it is the lowest. Considering that the total number of fast chargers $C_{a v}$ is much greater than the number of chargers needed in the sizing model, we assume that users can recharge immediately at charging stations and the calculation of $C_{2}$ is simplified so that the average charging time is assumed as the waiting time. The total social cost $C$ is utilized as an indicator to evaluate the optimal solutions, which equals the sum of the construction and investment costs of the charging stations and the waiting cost of the users.

\section{Feasibility Analysis Considering Slow Charging at Destinations}

The increase in slow charger coverage in the public parking lot will effectively reduce the fast charging demand, and the increase in EV ownership will, in turn, boost the fast charging demand. Therefore, in this study, based on the siting result of charging stations, we focus on the impact of the coverage of the slow charger and the growth of EV ownership on the fast charging demand. The time for slow charging of the EVs is subject to the probability density function in Equation (24) [23], and the MCS is applied to generate the slow charging time at each destination.

$$
f_{3}\left(t_{\text {slow }}\right)=\frac{\omega}{\eta P_{\text {slow }} t_{\text {slow }} \sigma_{3} \sqrt{2 \pi}} \exp \left(-\frac{\left(\ln \left(\frac{\eta P_{\text {slow }} t_{\text {slow }}}{\omega}\right)-\mu_{3}\right)^{2}}{2 \sigma_{3}^{2}}\right),
$$

where $\omega$ indicates the power consumption of EV per $100 \mathrm{~km} . \eta$ represents the charging efficiency. $P_{\text {slow }}$ is the slow charger rated power. $t_{\text {slow }}$ is the slow charging time and $\mu_{3}$ denotes the expected slow charging time. $\sigma_{3}$ is the standard deviation, $\mu_{3}=3.5, \sigma_{3}=0.8$.

The probability of slow charging at the destination reflects the coverage of slow chargers in the public parking lot, considering it's difficult to determine whether a user can be charged at the destination based on the coverage of slow chargers, while it is certain that a relationship exists between the coverage of slow chargers and the probability of slow charging. The slow charging time at destination $i$ is recorded as $t_{s l o w, i}$ and the added travel range $d_{e i}$ is shown in Equation (25). The maximum travel range of EVs will be updated according to Equation (26) and we continue with the trip feasibility analysis described in Section 3.3.

$$
\begin{gathered}
d_{e, i}=\min \left(\frac{t_{\text {slow }, i} P_{\text {slow }, i}}{P_{e v}} R, d_{o i}\right), \\
R=R+d_{e, i},
\end{gathered}
$$

where $d_{o i}$ indicates the mileage that has been traveled from the previous charging station to the newly arrived destination. $t_{\text {slow }, i} P_{\text {slow }, i}$ represents the energy recharged at destination $i$ through slow charging and Equation (25) turns the energy recharged into the added driving range.

Figure 12 explains that the charging choice and analysis of route feasibility depend on whether we consider slow charging at the destination. Figure 12a shows the situation when slow charging is not considered while Figure $12 \mathrm{~b}$ is for the situation when slow charging is considered. From Figure 12b, we can see that the time for slowing charging at destination $\mathrm{D}_{2}$ is $t_{\text {slow }}$. The added travel range $d_{e}$ after charging and the maximum travel range $R$ could be obtained via Equations (25) and (26). With the optimization method and analysis approach proposed in Section 3, we know that the user could successfully reach destination $\mathrm{D}_{3}$ and the trip would be a success. While in the situation Figure 12a 
without considering slow charging, the user cannot reach destination $\mathrm{D}_{3}$ directly and would have to charge at charging station $\mathrm{C}_{4}$ to continue with the journey.

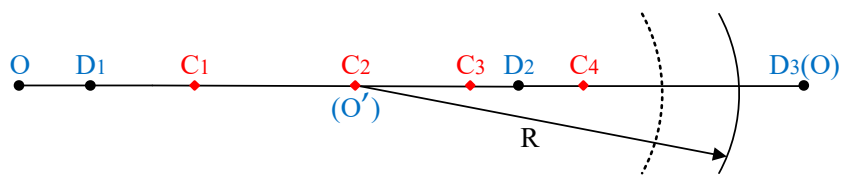

(a)

Slow charge at $\mathrm{D}_{2}$

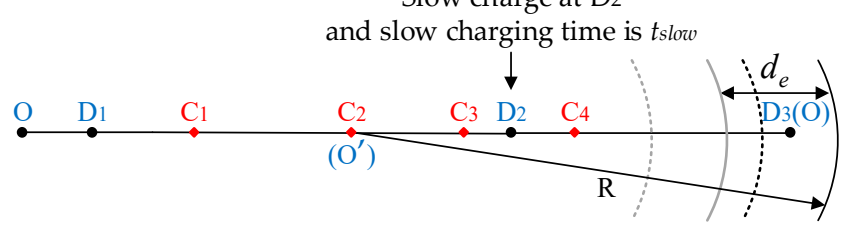

(b)

Figure 12. The feasibility analysis of the trip chain considering slow charge; (a) analyze the feasibility of the trip chain without considering slow charge; (b) analyze the feasibility of the trip chain considering slow charge.

\section{Case Study}

\subsection{Planning Area}

The bi-level planning model proposed is applied to an area of $45 \times 45 \mathrm{~km}^{2}$, as shown in Figure 13 . The planning area comprises of three parts: commercial area, industrial area and residential area, and includes 81 traffic nodes. For the commercial area, 20 nodes; the industrial area, 31 nodes; and 30 nodes for the residential area. It would be better to set the charging stations around the traffic nodes than on the road [22]. Therefore, in this study, all the traffic nodes are the candidate locations of the charging stations. For the actual construction, the location could be adjusted around the traffic node. The IEEE 123-node distribution test system is used as the corresponding power grid, which could be found in [45]. The maximum allowable voltage drop is $7 \%$ and over-voltage up to $5 \%$.

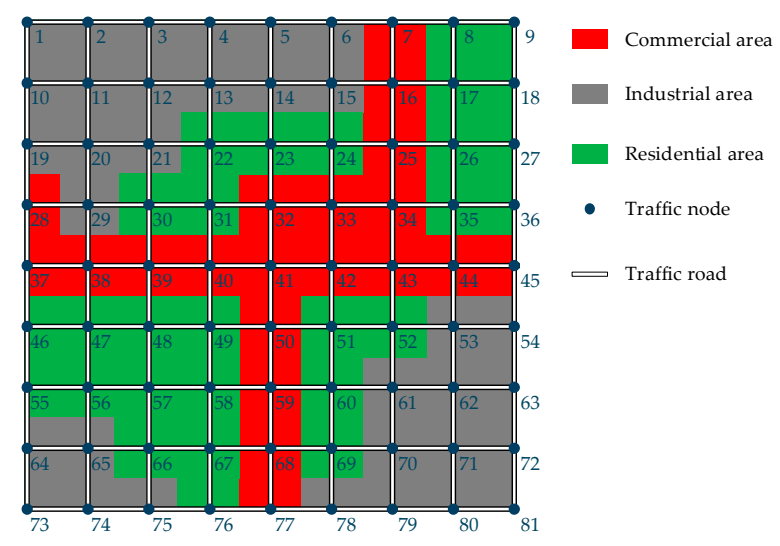

Figure 13. The planning area.

The study parameters are shown in Table 2 . The fixed investment cost for the charging stations at different levels rated according to the number of fast chargers after sizing is shown in Table 3 [40]. Land rental cost and time cost in different areas can be found in Table 4. 
Table 2. The study parameters.

\begin{tabular}{ccc}
\hline Parameter & Value & Unit \\
\hline$p$ & 4 & - \\
$n_{c \max }$ & 2 & - \\
$P_{\text {ev }}$ & $15[25]$ & $\mathrm{kWh}$ \\
$P_{\text {slow }}$ & $3.5[23]$ & $\mathrm{kW}$ \\
$\omega$ & $15[23]$ & $\mathrm{kWh} / 100 \mathrm{~km}$ \\
$\eta$ & $0.9[46]$ & - \\
$R$ & 100 & $\mathrm{~km}$ \\
$\lambda$ & 0.1 & - \\
$d_{\text {min }}$ & 10 & $\mathrm{~km}$ \\
$P_{c h}$ & $96[47]$ & $\mathrm{kW}$ \\
$s$ & $30[48]$ & $\mathrm{m}{ }^{2}$ \\
$C_{a v}$ & 100 & - \\
$C_{c o n}$ & $208.33[17]$ & $\$ / \mathrm{kW}$ \\
\hline
\end{tabular}

Table 3. The fixed investment cost with different levels.

\begin{tabular}{ccc}
\hline Station Level & Fixed Investment $\operatorname{Cos} \mathbf{t} / \times \mathbf{1 0}^{\mathbf{3}} \mathbf{\$}$ & Minimum Number of Chargers \\
\hline 1 & 1061 & 45 \\
2 & 800 & 30 \\
3 & 477 & 15 \\
4 & 323 & 8 \\
\hline
\end{tabular}

Table 4. Land rental cost and time cost of users in different areas.

\begin{tabular}{cccc}
\hline Area Type & Residential Area & Industrial Area & Commercial Area \\
\hline Land rental cost $\left(\$ / \mathrm{m}^{2}\right)[40]$ & 330 & 109 & 1070 \\
Time cost $(\$ / \mathrm{h})$ & $5.76[49]$ & 5.25 & 3.82 \\
\hline
\end{tabular}

\subsection{Simulation Results Considering Only Fast Charging}

Based on the travel pattern model, we obtain 113 sets of traveling data of users whose travel range exceeds the maximum travel range of EVs. In the upper model, the population size of the algorithm is set to be 100 , and the iteration times is 50 . The algorithm is run independently 10 times and the set with the highest success ratio is the feasible solution. Accordingly, we obtain nine sets of feasible solutions with a success ratio of $85.84 \%$. Later, we determine the optimal routs and optimal charging strategy for each user according to Sections 3.3 and 5.1. Moreover, we adopt the hybrid method to determine the capacity of the charging stations. The charging stations are rated according to the sizing results. The nine planning schemes are shown in Table 5, and the locations of these charging stations in the corresponding power grid are shown in Figure 14.

Table 5. The siting results of the lower model.

\begin{tabular}{cccc}
\hline Feasible Solutions & Siting Results & Number of Chargers & Rank of Charging Stations \\
\hline 1 & $25,33,41,57$ & $29,23,24,24$ & $3,3,3,3$ \\
2 & $25,42,41,57$ & $34,18,22,26$ & $2,3,3,3$ \\
3 & $48,25,58,70$ & $36,32,24,8$ & $2,2,3,4$ \\
4 & $48,25,58,69$ & $36,32,24,8$ & $2,2,3,4$ \\
5 & $48,24,35,58$ & $39,29,13,19$ & $2,3,4,3$ \\
6 & $48,24,71,58$ & $35,35,9,21$ & $2,2,4,3$ \\
7 & $48,25,69,58$ & $38,34,8,20$ & $2,2,4,3$ \\
8 & $41,57,35,39$ & $37,32,23,8$ & $2,2,3,4$ \\
9 & $25,50,42,65$ & $38,26,13,23$ & $2,3,4,3$ \\
\hline
\end{tabular}




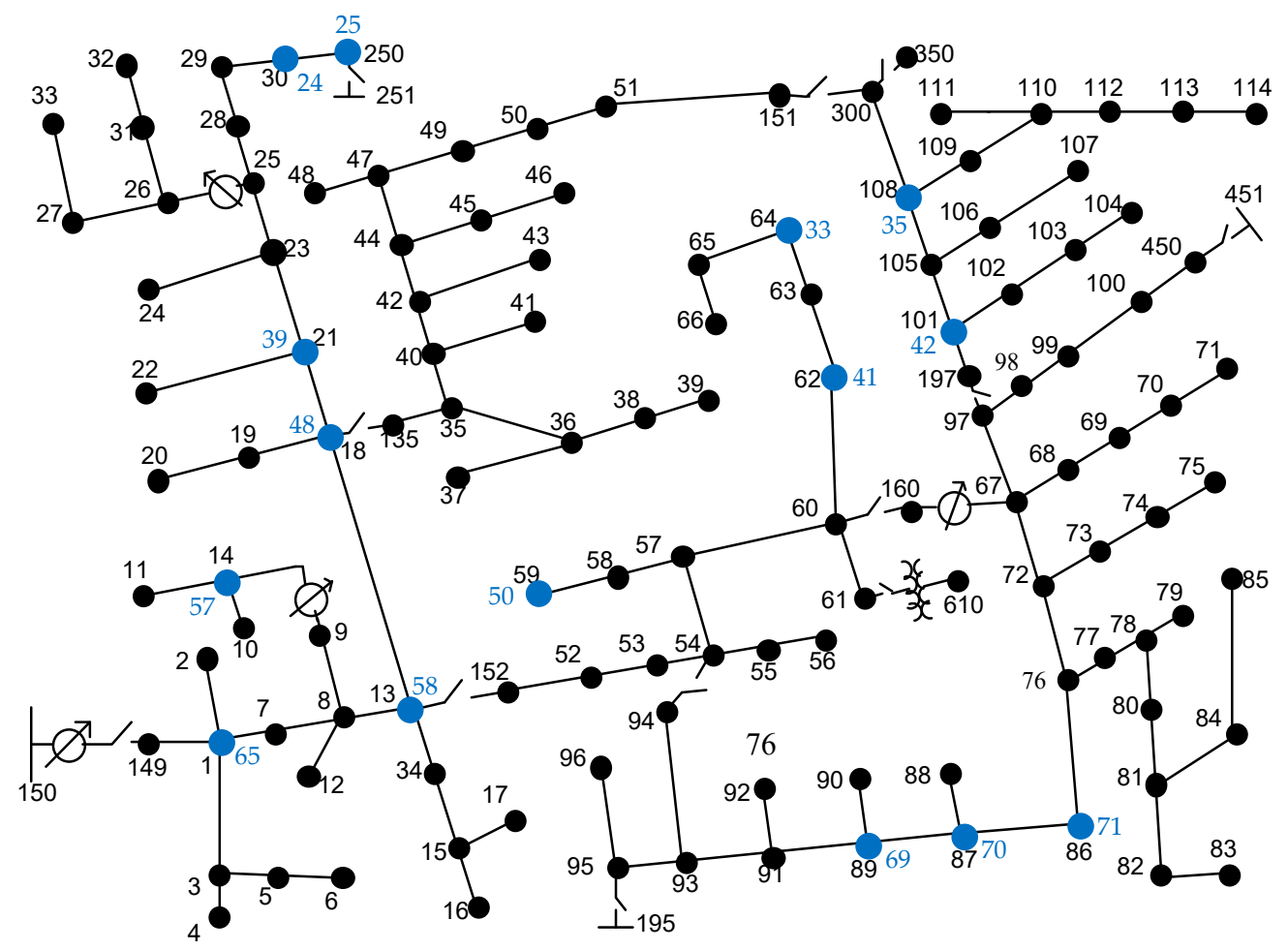

Figure 14. The locations of potential charging stations in the power grid.

Based on the locations in the power grid and the capacity of charging stations, we check the grid constraints and find that only solutions 3-7 can meet the power grid constraints. After the constraint test, we are able to work out the total social cost $C$ and the satisfaction index $r$ of the five feasible solutions via Equations (20)-(23), The result is shown in Figure 15, and the detailed total social cost is shown in Figure 16.

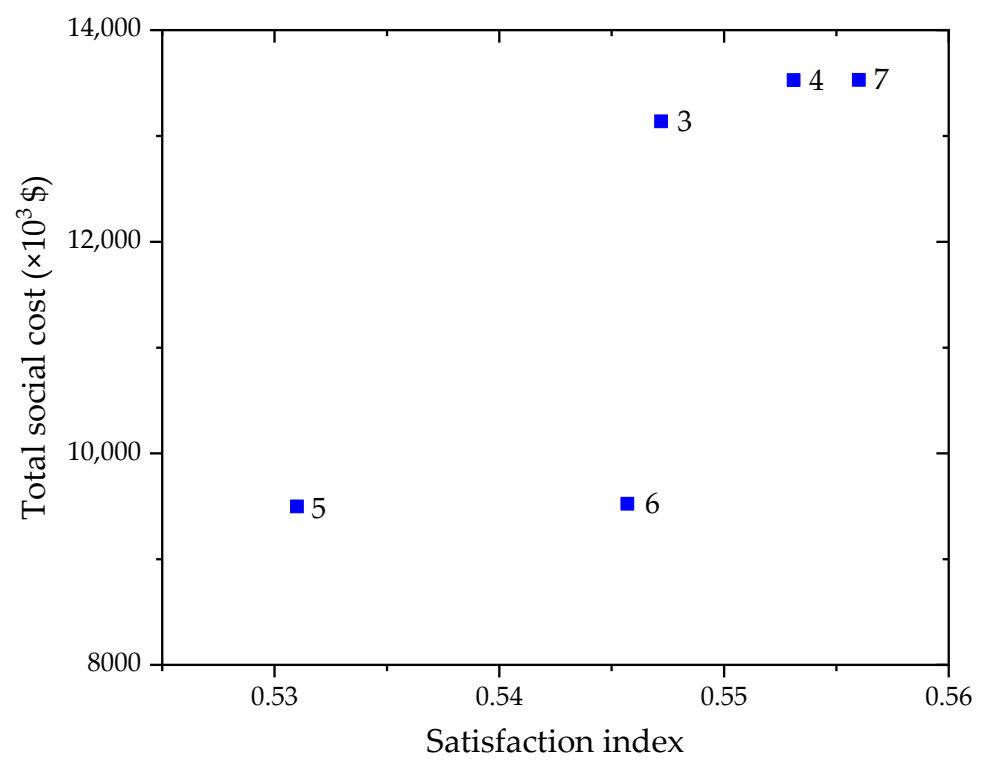

Figure 15. The total social cost and satisfaction index. 


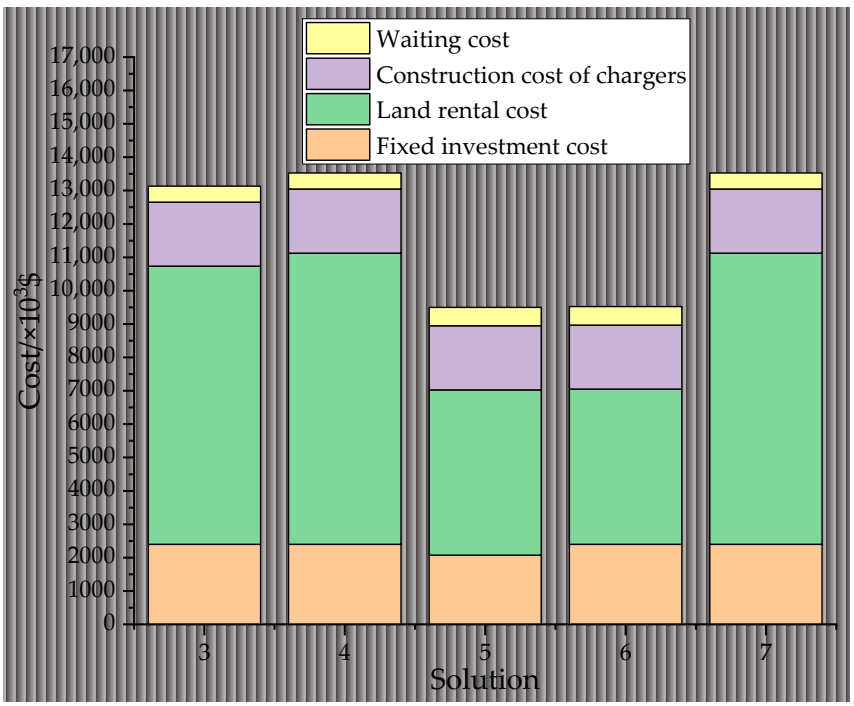

Figure 16. The detailed total social cost for each solution.

From Figure 15, we can see that the fifth solution has an overwhelming economic benefit and social benefit. Accordingly, the fifth planning scheme is chosen as the final planning scheme. It is worth noting that there is no Pareto curve in Figure 15, and we regard the fact that input solutions were screened in the upper model and the number of input solutions is limited as the primary reasons. Additionally, the two indicators have no stationary relationship and a multi-objective model is necessary to obtain the optimal solution. Furthermore, the situation demonstrates the good performance of the fifth solution. Although the contradiction between users and charging stations has been considered in the form of the waiting cost in the total social cost, from Figure 16, we notice that the waiting cost of users has little influence on the total social cost while the land rental cost is an essential part of the total social cost. The siting result is shown in Figure 17, and we can know that the charging stations are all placed in the residential area considering the cheap land rental cost. The locations of charging stations in the power grid is shown in Figure 18.

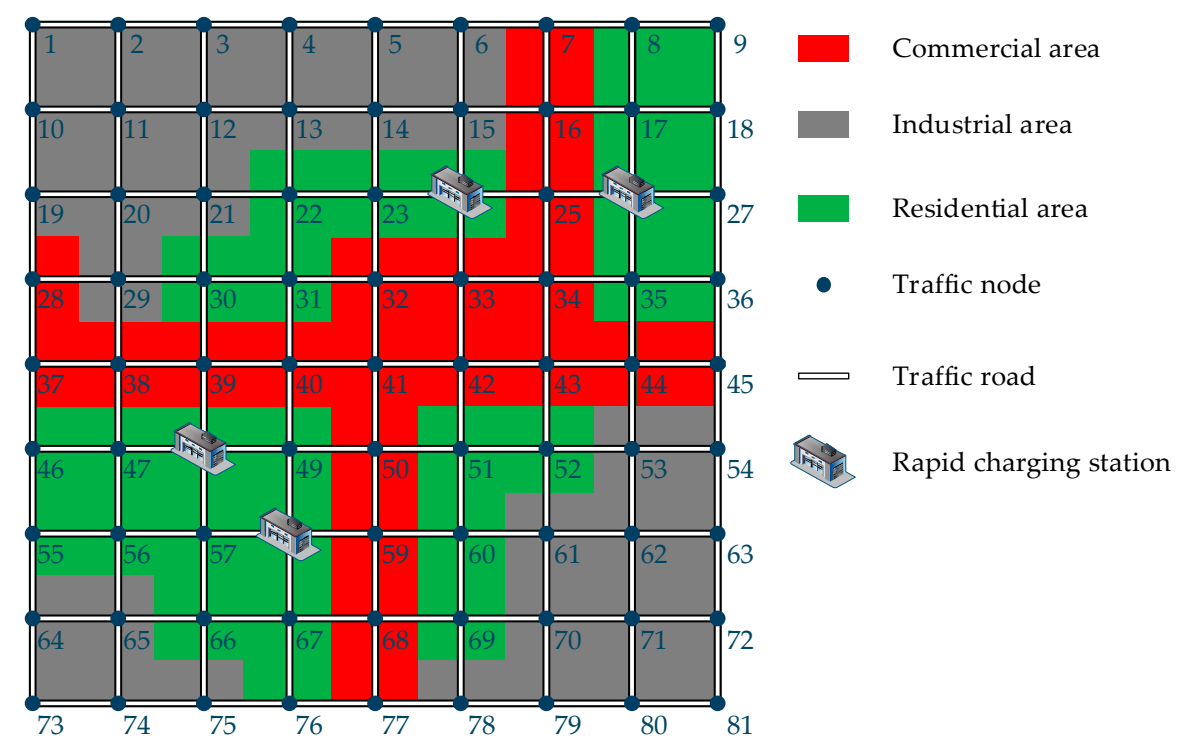

Figure 17. The siting results. 


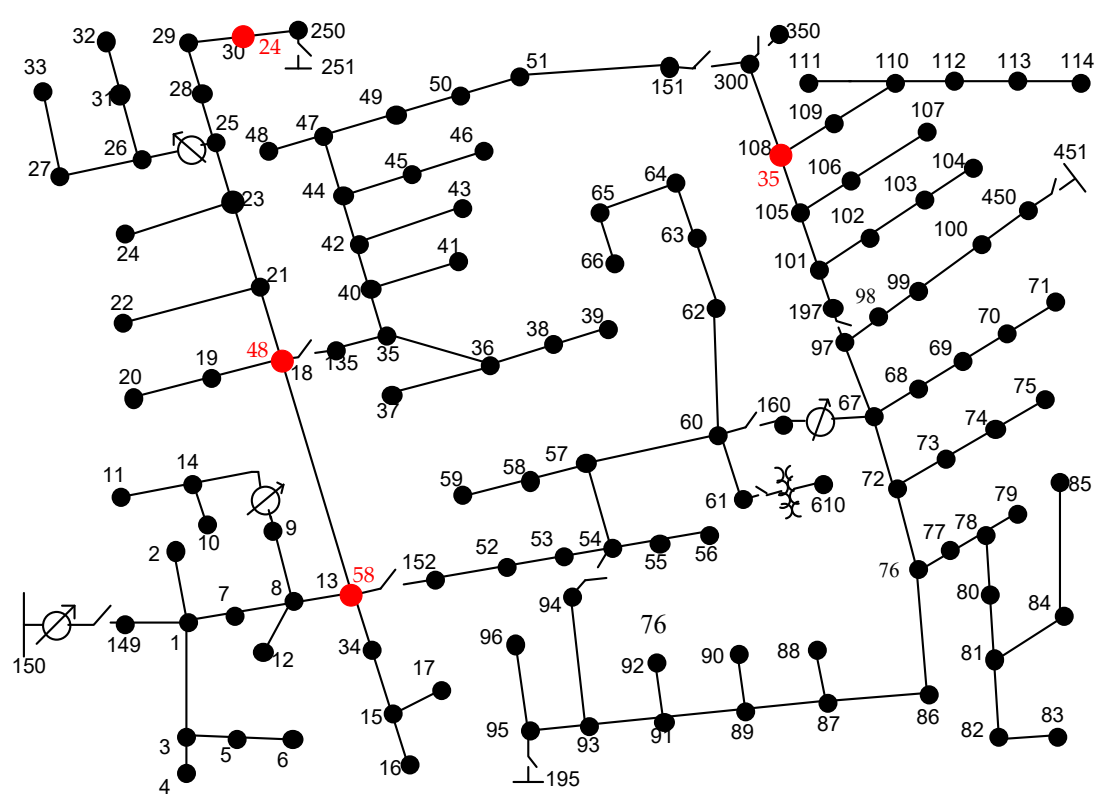

Figure 18. The locations of EV charging stations in the power grid.

The traffic flows of each traffic node before the planning, (that is, the EV users adopting the shortest path) and after the planning of the fast charging stations are shown in Figure 19a,b. From Figure 19, we can conclude that the siting of the charging stations will greatly influence the traffic flow as it has altered the travel route of some users and brought a greater traffic flow to the charging stations.

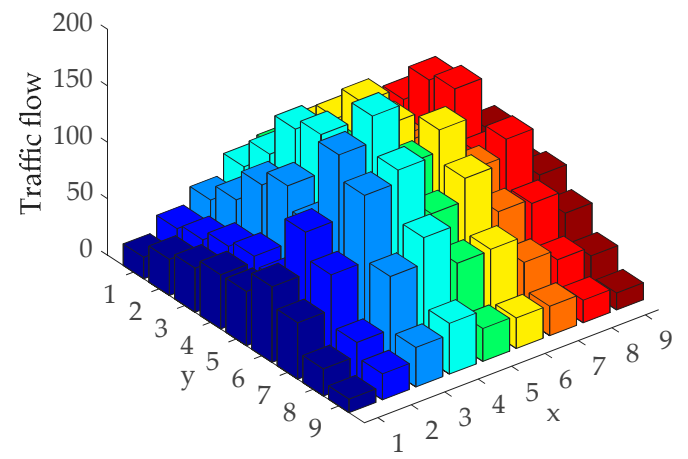

(a)

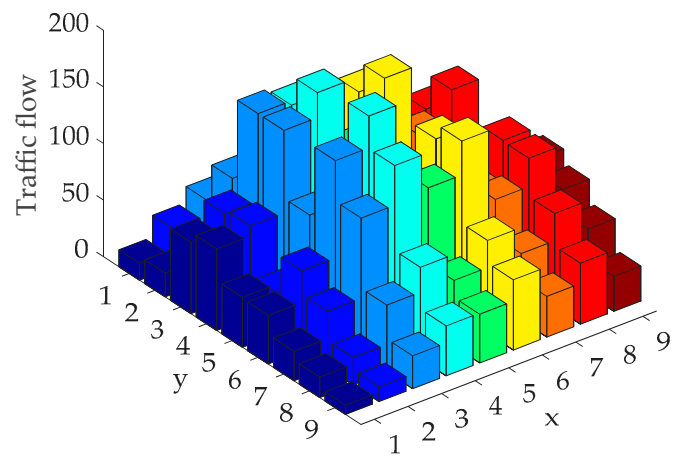

(b)

Figure 19. The traffic flow of each traffic node before and after the planning of the fast charging stations; (a) the traffic flow before the planning of the fast charging stations; (b) the traffic flow after the planning of the fast charging stations

\subsection{Simulation Results Using FCLM}

FCLM is applied to the planning area for the siting of the charging stations, which means that the travel route is the shortest path and the trip is captured only if at least one charging station on the path. With the algorithm proposed, we find that the travel success ratio at the maximum traffic flow is $80.53 \%$. In this study, we choose one planning scheme and plan to sit the charging stations at four traffic nodes: $17,56,66$, and 52 .

For this planning scheme, we adopt the method described in Section 3.3 to analyze the actual trip feasibility for each user choosing the shortest path, and the travel success ratio is obtained at $54.87 \%$, that is, $25.66 \%$ of EV users will be captured in FCLM and their trips are assumed to be successful, while, in fact, the charging station planning scheme cannot satisfy their travel demands. 
Then we consider the impact of charging stations on travel routes. We consider the possibility of detouring and re-planning the users' travel routes, and we obtain a travel success ratio of $75.22 \%$. The result demonstrates that $25.35 \%$ of the users can complete the trip by taking a detour.

The success ratio under the above three scenarios is shown in Figure 20. It can be seen that the above three scenarios have a great impact on the travel success ratio. Under different scenarios, planning the fast charging stations for a maximum travel success ratio will also produce different results. Scenario 1 does not consider the trip feasibility with a simple model; Scenario 2 does analyze the trip feasibility, but ignores the impact of the siting of the charging stations on the travel routes; and Scenario 3, which considers the trip feasibility and other potential travel routes, is most consistent with the actual situation.

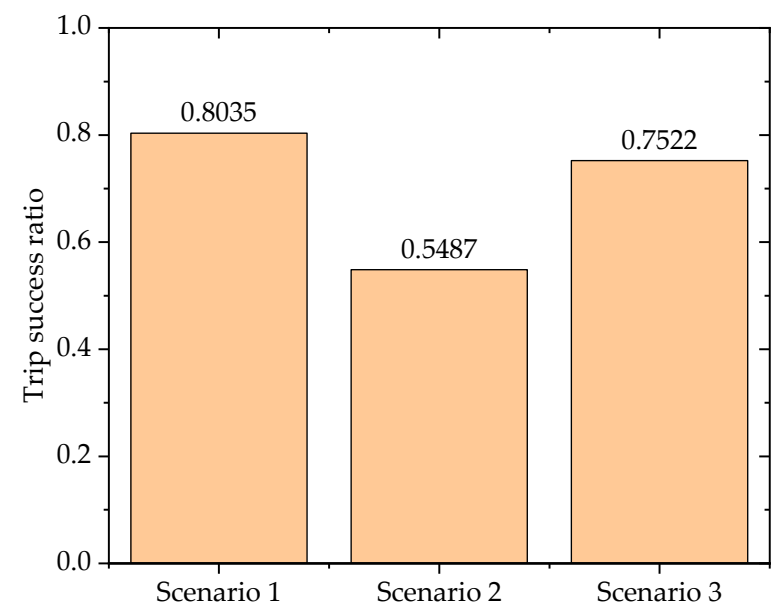

Figure 20. The travel success ratio under the three scenarios.

\subsection{Simulation Results Considering Slow Charging at Destinations}

Based on the slow charging probability and Equation (24), we employ the MCS to determine whether the user can slow charge at each destination and how long it will take. When the slow charging probability is 0 , the result is shown as in Section 7.2. Based on the siting result of the fast charging stations in Section 7.2, under the different slow charging probabilities, we re-analyze the trip feasibility of the above-mentioned traveling data. The travel success ratios under different slow charging probabilities would be the average result of running the MCS 10 times independently, as shown in Figure 21.

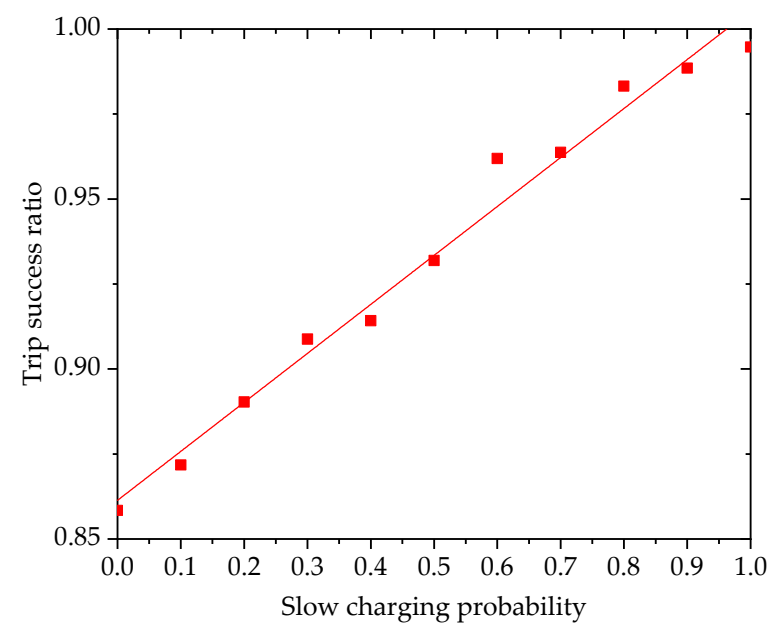

Figure 21. The travel success ratio under different slow charging probabilities. 
From Figure 21, we can see that the increase in the slow charging probability at the destination, that is, the increase of the slow charger coverage in the public parking lot, will lead to a proportional growth in the travel success ratio. Figure 22 shows a fitting chart showing the proportion of users who do not need to charge and the proportion of users who need to take a detour to recharge under different slow charging probabilities. As can be seen from the figure, with the increase in the coverage of slow chargers in the public parking lot, there will be more and more users who do not need to charge their vehicles on daily trips and the number of users who take a detour to charge will also decrease, which means that the increase in the slow charger coverage in the public parking lot will effectively reduce the fast charging times of the users and greatly saves their time. Moreover, from the decreasing proportion of users who need to take a detour to charge, we can see that it would be more convenient for the users and greatly improve the user experience. In addition, the growth in the coverage of slow chargers will lead to a sharp increase in the travel success ratio, thus making up for the limited travel range of EVs compared to traditional fuel vehicles and improving public recognition of EVs. At the same time, considering the higher cost of electricity for fast charging, the construction of slow chargers is more economical and effective for users.

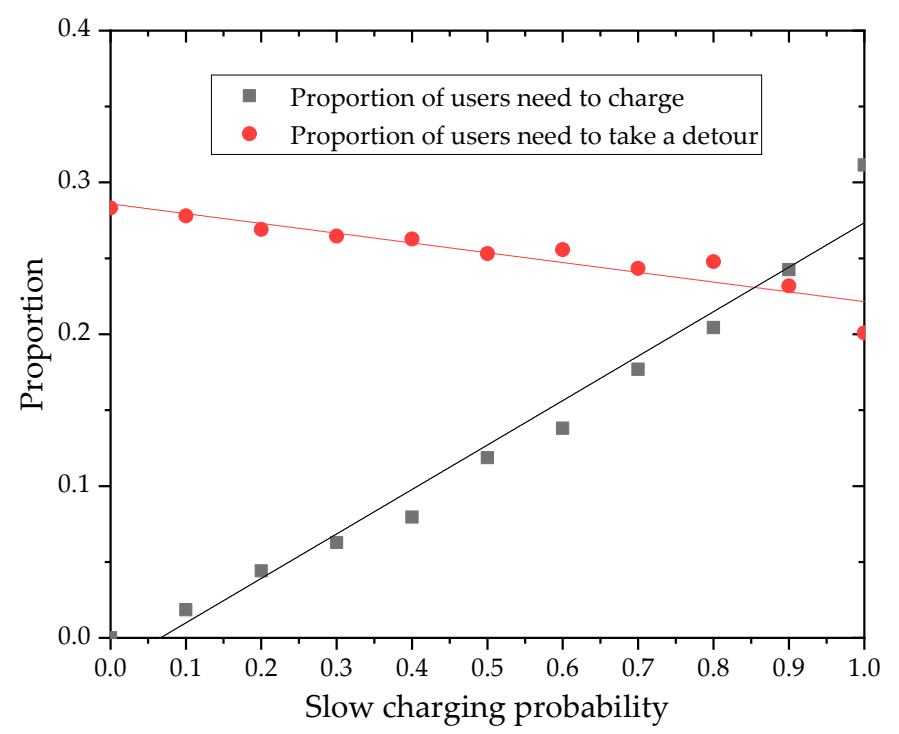

Figure 22. The influence on users under different slow charge probabilities.

With the large-scale popularization of future EVs, EV ownership will experience a sharp increase, as will the fast charging demand. Figure 23 shows the fast charging demands under different slow charging probabilities and the different growth rates of EVs at $0 \%, 15 \%, 30 \%$, and $50 \%$. From Figure 23 , we can conclude that the large-scale construction of slow chargers in public parking lots would significantly reduce the fast charging demand brought by the increase of EV ownership, relieving the pressure on the fast charging stations. 


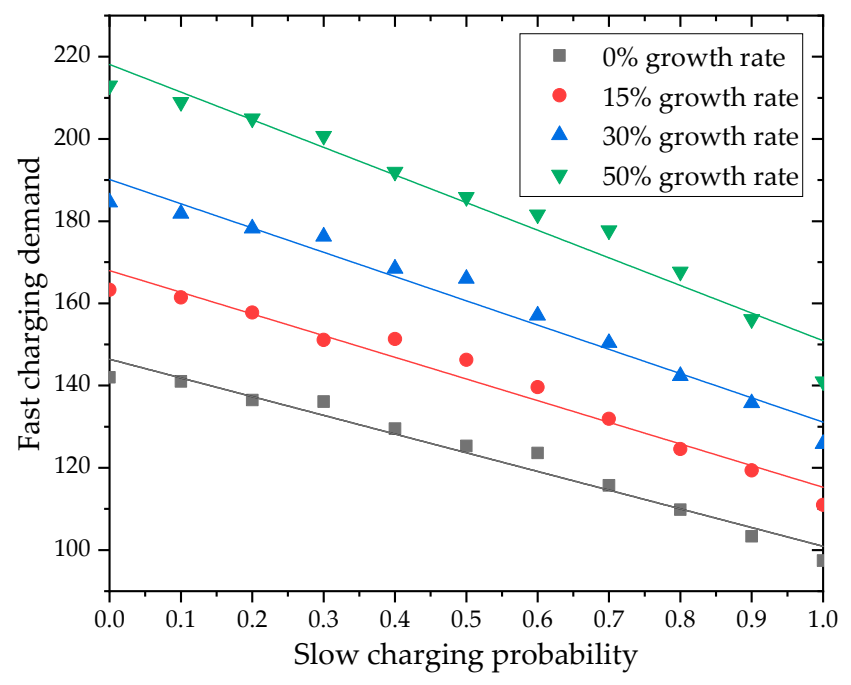

Figure 23. The fast charging demand under different slow charging probabilities.

\section{Conclusions}

In this study, we propose a method in which the shortest path is the primary choice. When it cannot meet the EV user's travel demand, we suggest other paths within certain deviation, which is more consistent with the actual situation. Compared with the traditional planning approach that only considers the shortest path, the proposed method effectively increases the travel success ratio. Moreover, through the optimization method, we manage to simulate the process of users heading for charging stations and obtain the number of the EVs served at each charging station, which leads to a more reliable sizing. For the upper model, we arrange the siting of the charging stations to reach the maximum travel success ratio. For the lower model, a hybrid method based on queuing theory and the greedy algorithm is applied to the sizing of charging stations, and the impact of charging stations on the power grid is also considered. Based on two indicators, the total social cost of charging stations and the satisfaction index, we successfully obtain the optimal planning scheme after evaluating all the feasible solutions.

The simulation result verifies the feasibility and rationality of the proposed model, as well as the impact of the siting of the charging stations on travel routes. The FCLM is also applied to the siting of the planning area and the travel success ratio is $80.53 \%$ at the maximum flow captured. Based on the FCLM siting result, we take into consideration the trip feasibility and re-evaluate whether EV users could finish their trip successfully. From the evaluation, we obtain a travel success ratio of $54.87 \%$, far below $80.53 \%$, which proves that FCLM is too simple to be consistent with the actual situation. Additionally, we also consider that the co-existence of multiple travel routes are available, which leads to a travel success ratio of $75.22 \%$, indicating that the siting of the charging stations will significantly influence users' travel routes and the travel success ratio. Furthermore, based on the same aim of reaching the maximum success ratio, the planning results vary under different situations.

In addition, we study the impact of slow charger coverage in the public parking lot on the fast charging demand and EV users. The result concludes that the higher the slow charger coverage achieves, the lower the fast charging demand is, along with the higher the travel success ratio, which will greatly improve the user's experience. The combination of slow chargers and fast charging stations can effectively make up for the limited maximum travel range of EVs compared to fuel vehicles, which will facilitate the popularization of EVs. With the increase of EVs, the fast charging demand will also raise sharply. In this study, we focus on the fast charging demand of EVs under different growth rates of EVs and different coverage rates of the slow chargers, conclude that large-scale construction of slow chargers in the public parking lot can effectively reduce the charging pressure on the fast charging stations that is brought about by the increase in the number of EVs. 
We mainly study the siting and sizing of the fast charging stations, and conduct preliminary research on the impact of slow charger coverage on the travel pattern of EV users and the rapid charging demand in public parking lot. Future research will center on the overall planning and research of the multiple charging modes of EVs.

Author Contributions: H.Z. and Y.F. conceived and designed the experiments and wrote the paper; M.C. and H.S. performed the experiments; L.M. and S.Z. analyzed the data; and Z.W. and G.S. contributed reagents/materials/analysis tools.

Funding: The research is supported by National Natural Science Foundation of China (Program No. 51507052), the Fundamental Research Funds for the Central Universities (Program No. 2018B15414), Jiangsu Key Laboratory of Smart Grid Technology and Equipment, and Science and Technology project of State Grid Jiangsu Electric Power Co., Ltd. (J2017092).

Conflicts of Interest: The authors declare no conflict of interest.

\section{References}

1. Chen, Q.; Liu, N.; Wang, C.; Zhang, J. Optimal power utilizing strategy for pv-based ev charging stations considering real-time price. In Proceedings of the 2014 IEEE Conference and Expo Transportation Electrification Asia-Pacific (ITEC Asia-Pacific), Beijing, China, 31 August-3 September 2014; pp. 1-6.

2. U.S. Environmental Protection Agency. Greenhouse Gas Emissions from the U.S. Transportation Sector: 1990-2003. Available online: http:/ /www.epa.gov/otaq/climate/420r06003.pdf (accessed on 18 April 2018).

3. Christensen, T.B.; Wells, P.; Cipcigan, L. Can innovative business models overcome resistance to electric vehicles? Better place and battery electric cars in denmark. Energy Policy 2012, 48, 498-505. [CrossRef]

4. Aziz, M.; Oda, T. Simultaneous quick-charging system for electric vehicle. Energy Procedia 2017, 142, 1811-1816. [CrossRef]

5. Nie, Y.; Ghamami, M.; Zockaie, A.; Xiao, F. Optimization of incentive polices for plug-in electric vehicles. Transp. Res. Part B 2016, 84, 103-123. [CrossRef]

6. Kontou, E.; Yin, Y.; Lin, Z;; He, F. Socially optimal replacement of conventional with electric vehicles for the us household fleet. Int. J. Sustain. Transp. 2017, 11, 749-763. [CrossRef]

7. Singer, M. Consumer Views on Plug-In Electric Vehicles-National Benchmark Report; National Renewable Energy Laboratory: Golden, CO, USA, 2016.

8. Aziz, M.; Oda, T.; Mitani, T.; Watanabe, Y.; Kashiwagi, T. Utilization of electric vehicles and their used batteries for peak-load shifting. Energies 2015, 2015, 3720-3738. [CrossRef]

9. Lojowska, A.; Kurowicka, D.; Papaefthymiou, G.; Lou, V.D.S. Stochastic modeling of power demand due to evs using copula. IEEE Trans. Power Syst. 2012, 27, 1960-1968. [CrossRef]

10. Mu, Y.; Wu, J.; Jenkins, N.; Jia, H.; Wang, C. A spatial-temporal model for grid impact analysis of plug-in electric vehicles. Appl. Energy 2014, 114, 456-465. [CrossRef]

11. Liang, H.; Sharma, I.; Zhuang, W.; Bhattacharya, K. Plug-in electric vehicle charging demand estimation based on queueing network analysis. In Proceedings of the Pes General Meeting | Conference \& Exposition, National Harbor, MD, USA, 27-31 July 2014; pp. 1-5.

12. Bae, S.; Kwasinski, A. Spatial and temporal model of electric vehicle charging demand. IEEE Trans. Smart Grid 2012, 3, 394-403. [CrossRef]

13. Andrenacci, N.; Ragona, R.; Valenti, G. A demand-side approach to the optimal deployment of electric vehicle charging stations in metropolitan areas. Appl. Energy 2016, 182, 39-46. [CrossRef]

14. Dong, X.; $\mathrm{Mu}, \mathrm{Y} . ; \mathrm{Jia}, \mathrm{H} . ; \mathrm{Wu}, \mathrm{J} . ; \mathrm{Yu}, \mathrm{X}$. Planning of fast ev charging stations on a round freeway. IEEE Trans. Sustain. Energy 2016, 7, 1452-1461. [CrossRef]

15. Ip, A.; Fong, S.; Liu, E. Optimization for allocating bev recharging stations in urban areas by using hierarchical clustering. In Proceedings of the International Conference on Advanced Information Management and Service, Seoul, Korea, 30 November-2 December 2010; pp. 460-465.

16. Frade, I.; Ribeiro, A.; Gonçalves, G.; Antunes, A.P. Optimal location of charging stations for electric vehicles in a neighborhood in Lisbon, Portugal. Transp. Res. Rec. J. Transp. Res. Board 2011, 2252, 91-98. [CrossRef]

17. Sadeghi-Barzani, P.; Rajabi-Ghahnavieh, A.; Kazemi-Karegar, H. Optimal fast charging station placing and sizing. Appl. Energy 2014, 125, 289-299. [CrossRef] 
18. Xiang, Y.; Liu, J.; Li, R.; Li, F.; Gu, C.; Tang, S. Economic planning of electric vehicle charging stations considering traffic constraints and load profile templates. Appl. Energy 2016, 178, 647-659. [CrossRef]

19. Wang, G.; Xu, Z.; Wen, F.; Wong, K.P. Traffic-constrained multiobjective planning of electric-vehicle charging stations. IEEE Trans. Power Deliv. 2013, 28, 2363-2372. [CrossRef]

20. Berman, O.; Larson, R.C.; Fouska, N. Optimal location of discretionary service facilities. Transp. Sci. 1992, 26, 201-211. [CrossRef]

21. Hodgson, M.J. A billboard location model. Geogr. Environ. Modeling 1997, 1, 25-45.

22. Hodgson, M.J. A flow-capturing location-allocation model. Geogr. Anal. 2010, 22, 270-279. [CrossRef]

23. Wang, S.; Dong, Z.Y.; Luo, F.; Meng, K.; Zhang, Y. Stochastic collaborative planning of electric vehicle charging stations and power distribution system. IEEE Trans. Ind. Inform. 2016, 14, 321-331. [CrossRef]

24. Yao, W.; Zhao, J.; Wen, F.; Dong, Z.; Xue, Y.; Xu, Y.; Meng, K. A multi-objective collaborative planning strategy for integrated power distribution and electric vehicle charging systems. IEEE Trans. Power Syst. 2014, 29, 1811-1821. [CrossRef]

25. Kong, C.; Jovanovic, R.; Bayram, I.; Devetsikiotis, M. A hierarchical optimization model for a network of electric vehicle charging stations. Energies 2017, 10, 675. [CrossRef]

26. Riemann, R.; Wang, D.Z.W.; Busch, F. Optimal location of wireless charging facilities for electric vehicles: Flow-capturing location model with stochastic user equilibrium. Transp. Res. Part C 2015, 58, 1-12. [CrossRef]

27. Chung, S.H.; Kwon, C. Multi-period planning for electric car charging station locations: A case of korean expressways. Eur. J. Oper. Res. 2015, 242, 677-687. [CrossRef]

28. Kuby, M.; Lim, S. The flow-refueling location problem for alternative-fuel vehicles. Soc.-Econ. Plan. Sci. 2005, 39, 125-145. [CrossRef]

29. Awasthi, A.; Venkitusamy, K.; Padmanaban, S.; Selvamuthukumaran, R.; Blaabjerg, F.; Singh, A.K. Optimal planning of electric vehicle charging station at the distribution system using hybrid optimization algorithm. Energy 2017, 133, 70-78. [CrossRef]

30. Davidov, S.; Pantoš, M. Planning of electric vehicle infrastructure based on charging reliability and quality of service. Energy 2017, 118, 1156-1167. [CrossRef]

31. Nie, Y.; Ghamami, M. A corridor-centric approach to planning electric vehicle charging infrastructure. Transp. Res. Part B 2013, 57, 172-190. [CrossRef]

32. Huang, Y.; Li, S.; Qian, Z.S. Optimal deployment of alternative fueling stations on transportation networks considering deviation paths. Netw. Spat. Econ. 2015, 15, 183-204. [CrossRef]

33. Dong, J.; Liu, C.; Lin, Z. Charging infrastructure planning for promoting battery electric vehicles: An activity-based approach using multiday travel data. Transp. Res. Part C 2014, 38, 44-55. [CrossRef]

34. He, F.; Yin, Y.; Zhou, J. Deploying public charging stations for electric vehicles on urban road networks. Transp. Res. Part C 2015, 60, 227-240. [CrossRef]

35. Yang, J.; Dong, J.; Hu, L. A data-driven optimization-based approach for siting and sizing of electric taxi charging stations. Transp. Res. Part C 2017, 77, 462-477. [CrossRef]

36. Micari, S.; Polimeni, A.; Napoli, G.; Andaloro, L.; Antonucci, V. Electric vehicle charging infrastructure planning in a road network. Renew. Sustain. Energy Rev. 2017, 80, 98-108. [CrossRef]

37. Zhang, L.; Shaffer, B.; Brown, T.; Samuelsen, G.S. The optimization of dc fast charging deployment in california. Appl. Energy 2015, 157, 111-122. [CrossRef]

38. Wu, D.; Aliprantis, D.C.; Gkritza, K. Electric energy and power consumption by light-duty plug-in electric vehicles. IEEE Trans. Power Syst. 2011, 26, 738-746. [CrossRef]

39. U.S. Department of Transportation. National Household Travel Survey (NHTS). Available online: http:/ /nhts.ornl.gov/download.shtml (accessed on 1 January 2018).

40. Liu, Z.; Zhang, W.; Wang, Z. Optimal planning of charging station for electric vehicle based on quantum pso algorithm. Proc. CSEE 2012, 32, 39-45.

41. Steen, D.; Le, A.T.; Carlson, O.; Bertling, L. Assessment of electric vehicle charging scenarios based on demographical data. IEEE Trans. Smart Grid 2012, 3, 1457-1468. [CrossRef]

42. Grahn, P.; Munkhammar, J.; Widén, J.; Alvehag, K.; Söder, L. Phev home-charging model based on residential activity patterns. IEEE Trans. Power Syst. 2013, 28, 2507-2515. [CrossRef]

43. Hu, S.R.; Wang, C.M. Vehicle detector deployment strategies for the estimation of network origin-destination demands using partial link traffic counts. IEEE Trans. Intell. Transp. Syst. 2008, 9, 288-300. 
44. Qian, K.; Zhou, C.; Allan, M.; Yuan, Y. Modeling of load demand due to ev battery charging in distribution systems. IEEE Trans. Power Syst. 2011, 26, 802-810. [CrossRef]

45. Lotfifard, S.; Kezunovic, M.; Mousavi, M.J. Voltage sag data utilization for distribution fault location. IEEE Trans. Power Deliv. 2011, 26, 1239-1246. [CrossRef]

46. Liu, W.; Niu, S.; Xu, H.; Li, X. A new method to plan the capacity and location of battery swapping station for electric vehicle considering demand side management. Sustainability 2016, 8, 557. [CrossRef]

47. Ge, S.; Feng, L.; Liu, H. The planning of electric vehicle charging station based on grid partition method. In Proceedings of the International Conference on Electrical and Control Engineering, Yichang, China, 16-18 September 2011; pp. 2726-2730.

48. Islam, M.M.; Shareef, H.; Mohamed, A. Optimal siting and sizing of rapid charging station for electric vehicles considering bangi city road network in malaysia. Turkish J. Electr. Eng. Comput. Sci. 2016, 24, 3933-3948. [CrossRef]

49. Zhang, H.; Hu, Z.; Xu, Z.; Song, Y. An integrated planning framework for different types of pev charging facilities in urban area. IEEE Trans. Smart Grid 2017, 7, 2273-2284. [CrossRef]

(C) 2018 by the authors. Licensee MDPI, Basel, Switzerland. This article is an open access article distributed under the terms and conditions of the Creative Commons Attribution (CC BY) license (http:/ / creativecommons.org/licenses/by/4.0/). 